\title{
Tool electrode wear in electrical discharge of small diameter holes
}

\author{
Laurenţiu Slătineanu ${ }^{1}$, Oana Dodun ${ }^{1, *}$, Iulia Carp $^{1}$, Margareta Coteaţă ${ }^{1}$, and Irina Beşliu $^{2}$ \\ ${ }^{1}$ Department of Machine Manufacturing Technology, Gheorghe Asachi Technical University of Iasi, \\ Blvd. D. Mangeron, 39A, 700050, Iasi, Romania \\ ${ }^{2}$ Department of Mechanics and Technologies, University Stefan cel Mare of Suceava, Universitatii \\ Street 13, 720229 Suceava, Romania
}

\begin{abstract}
In the paper, the problem of obtaining small diameter holes in workpieces made of high speed steel by electrical discharge machining was formulated. A fulfil factorial experiment was designed and materialized, taking into consideration the tool electrode diameter, pulse on time and pulse off time as independent variables. The tool electrode wear was evaluated by means of the decrease of tool electrode mass and length. On the base of experimental results, power type empirical mathematical models were determined. One noticed the higher influence exerted by the too electrode diameter, whose increase determine the decrease of the tool electrode.
\end{abstract}

\section{Introduction}

Holes with distinct diameters and lengths must be sometimes achieved in metallic workpieces, in order to obtain certain pieces; these holes could be used when mobile or fix joins has to be ensured. It is known that the surfaces specific to cylindrical joins are easier obtained by machining processes if compared with joins involving other types of surfaces.

If the workpiece material has an acceptably machinability, the small diameter holes could be efficiently obtained by drilling. If the workpiece material has high mechanical properties (high ultimate strength, high hardness etc.) and when the holes diameters are lower than $1 \mathrm{~mm}$, the problem of obtaining these holes by nonconventional machining methods could be formulated. Thus, small diameter holes could be achieved by electrical discharge machining, electrochemical machining, laser beam machining, electron beam machining etc. Due to the presence in mechanical enterprises of equipment for electrical discharge machining, the electrical discharge machining method could be an acceptable and accessible solution applied in order to obtain small diameter holes.

The electrical discharge machining method is based on material removal from workpiece as a consequence of electrical discharges developed between the closest asperities existing on the active surface of tool electrode and surfaces to be machined of the workpiece. The particles detached from tool electrode and workpiece during electrical discharge machining process are removed from the work gap due to the circulation of a

\footnotetext{
*Corresponding author: oanad@tcm.tuiasi.ro
} 
dielectric fluid. Usually, there is at least a work movement achieved by the tool electrode or by the workpiece, so that the machined surface is an envelope of distinct positions of the tool electrode active surfaces during the machining process.

Jiang et al. considered [1] that an efficient small hole EDM process needs an accurate pulse monitoring strategy and a precise control. They used an adaptive control system and the wavelet transform detecting method in order to accurately identify the pulses. They appreciated that the machining process involves two stages, one in which the debris generated by the discharges can be easily removed from the discharge gap and a second stage, when the adaptive control system could reduce the arc pulse ratio, in order to improve the process efficiency and the quality of small-hole drilling process.

D'Urso et al. developed [2] an investigation aiming to highlight the influence of peak current, voltage and pulse frequency at micro-EDM drilling of stainless steel plates by using tubular tool electrodes having the outer diameter of $0.3 \mathrm{~mm}$ and inner diameter of $0.12 \mathrm{~mm}$. They established some mathematical models able to show how the process input factors affect the material removal rate and tool wear ratio. Two technological windows corresponding to the influence exerted by hole depth on tool wear ratio and material removal rate were elaborated.

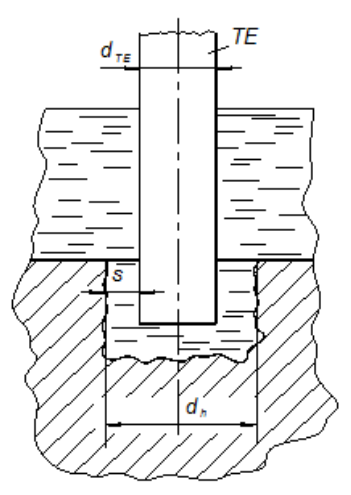

a)

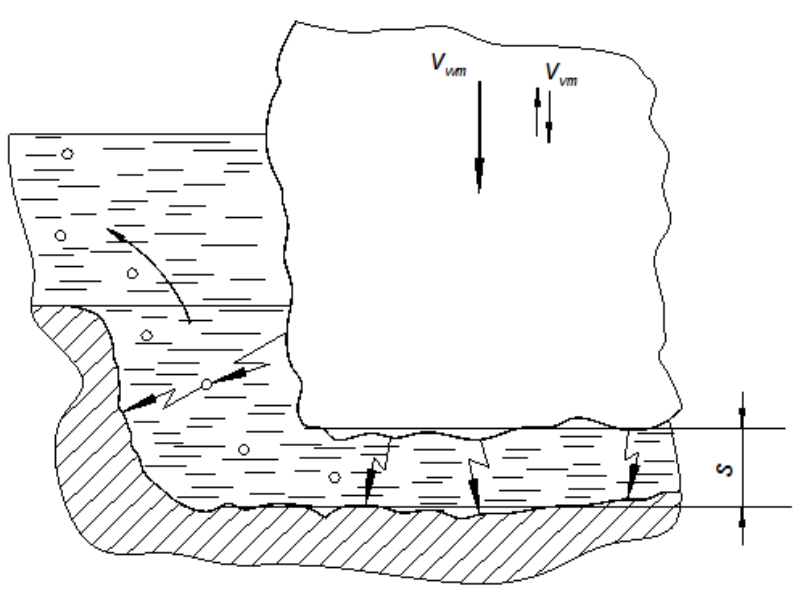

b)

Fig. 1. Work zone in the case of obtaining small diameter holes by electrical discharge machining: a) principle scheme; b) tapering of hole entering zone as a consequence of spurious electrical discharges.

\section{Theoretical premises}

In order to obtain small diameter holes by electrical discharge machining, wire type tool electrode could be used. The machining schema corresponding to electrical discharge machining of small diameter holes is presented in Fig. 1. Usually the wire tool electrode is clamped in a chuck attached to the work head of the electrical discharge machine, while the workpiece is placed directly on the table of machine-tool or it can be clamped in a vice placed on the machine tool table.

The tool electrode achieves a linear movement together with the machine tool head to the workpiece; the subsystem for achieving the work movement ensures maintaining of a pre-established distance between the tool electrode active surface and the surface to be machined of the workpiece. Over the low speed work movement $v_{w m}$ of the machine work 
head, a rectilinear reciprocating movements $v_{v m}$ is overlapped, in order to contribute to the removal of particles detached from tool electrode and workpiece by phenomena of absorption - pressing.

The tool electrode achieves a linear movement together with the machine tool head to the workpiece; the subsystem for achieving the work movement ensures maintaining of a pre-established distance between the tool electrode active surface and the surface to be machined of the workpiece. Over the low speed work movement $v_{w m}$ of the machine work head, a rectilinear reciprocating movements $v_{v m}$ is overlapped, in order to contribute to the removal of particles detached from tool electrode and workpiece by phenomena of absorption - pressing.

As a consequence of the electrical discharges developed between tool electrode and workpiece, a material removal process develops not only from the workpiece, but also from the tool electrode. Usually, the tool electrode is achieved of materials characterized by a low machinability by electrical discharge machining, just in order to diminish the tool electrode wear. An image about the machinability by electrical discharge machining is offered [3] by the value of the so called Palatnik's criterion:

$$
\pi=c \rho \lambda \theta_{m}^{2}
$$

where $c[\mathrm{~J} /(\mathrm{kg} \cdot \mathrm{K})]$ is the specific heat of the workpiece material, $\rho\left[\mathrm{kg} / \mathrm{m}^{3}\right]$ - the workpiece material density, $\lambda[\mathrm{W} /(\mathrm{m} \cdot \mathrm{K})]-$ the coefficient of thermal conductivity, $\theta_{m}[\mathrm{~K}]-$ the absolute melting temperature.

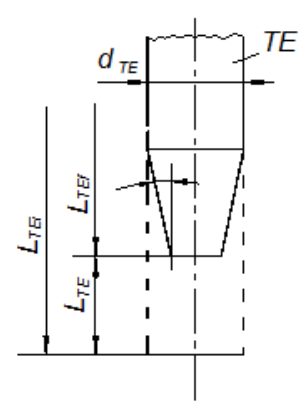

a)

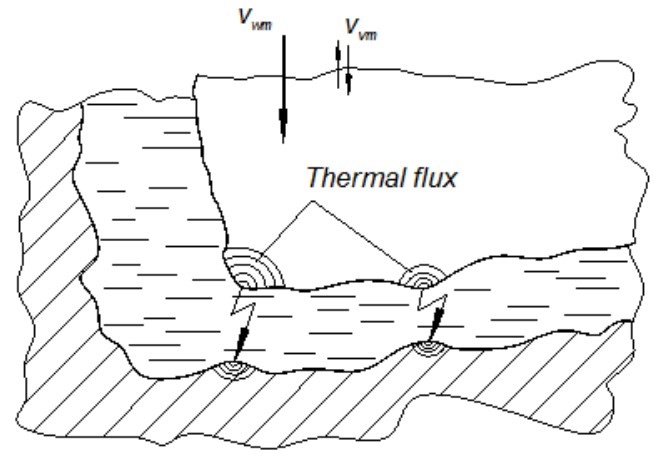

b)

Fig. 2. More intense wear of tool electrode edges and shape change as a consequence of wear phenomenon:

a) active zone of tool electrode;

b) heat dissipation at the tool electrode edge and near the tool electrode axis.

If one considers two materials for tool electrode (steel and copper) and takes into consideration the values specific to these materials (in the case of steel, $\mathrm{c}=420 \mathrm{~J} /(\mathrm{kg} \cdot \mathrm{K}$ ), $\rho=7850 \mathrm{~kg} / \mathrm{m} 3, \lambda=54 \mathrm{~W} /(\mathrm{m} \cdot \mathrm{K}), \theta \mathrm{m}=1755 \mathrm{~K}$, and in the case of copper, $\mathrm{c}=385 \mathrm{~J} /(\mathrm{kg} \cdot \mathrm{K})$, $\rho=8933 \mathrm{~kg} / \mathrm{m} 3, \lambda=401 \mathrm{~W} /(\mathrm{m} \cdot \mathrm{K}), \theta \mathrm{m}=1358 \mathrm{~K})$, one can find $\pi$ steel $=5.48361 \cdot 1014$ and $\pi$ copper $=2.543 \cdot 1015$; because the ratio $\pi$ cooper/ $\pi$ steel $=4.638$, this means that a tool electrode made of steel will be affected by a wear more intense than 4.5 times compared with the wear of tool electrode made of copper. 
A supplementary factor able to affect the development of the material removal from tool electrode is the possibility of evacuation the high quantity of heat generated by each electrical discharge. If in the zones close to the tool electrode axis there is the possibility of heat dissipation in the tool electrode metallic mass, in the zones found near the edge existing between the tool electrode frontal place surface and the cylindrical surface, there is not a possibility of efficient dissipation of the heat (Fig. 2) and such a fact determines a more intense process of heating and of material removal. Thus, in time, a decrease of tool electrode length and a tapering of the former sharp edge could be expected (Fig. 2, a).

Problems could be also generated by the metallic particles movements between the side cylindrical surface of the tool electrode and the cylindrical surface gradually generated in the workpiece. Along their motions in the side gap, the metallic particles could generate spurious electrical discharges along the trajectory including the tool electrode, metallic particle and workpiece. The spurious electrical discharges could contribute to a supplementary material removal from the workpiece and this could generate a tapering of the hole entering zone (Fig. 1, $b$ ).

The problem of hole shape error appears especially when long holes must be obtained by electrical discharge machining.

As one can see, the diameter of the tool electrode $d_{T E}$ could be determined as the following difference:

$$
d_{T E}=d_{h}-2 s
$$

where $s$ is the size of the work gap and $d_{h}$ - hole diameter.

Being an important output parameter, the tool electrode wear was studied, in order to determine which are the influence factors and how the tool electrode wear could be diminished.

Table 1. Values of the input factors and output parameters in the case of obtaining small diameter holes by electrical discharge machining (machining process duration: 40 min, test piece made of high speed steel HS14-0-1-4).

\begin{tabular}{|c|c|c|c|c|c|c|c|c|}
\hline \multirow{3}{*}{$\begin{array}{l}\text { Exp. } \\
\text { No. }\end{array}$} & \multicolumn{6}{|c|}{ Input factors } & \multirow{3}{*}{$\begin{array}{c}\text { Decrease } \\
\text { of tool } \\
\text { electrode } \\
\text { mass, } \\
\Delta m_{T E}, \\
{[\mathrm{~g}]}\end{array}$} & \multirow{3}{*}{$\begin{array}{c}\text { Decrease } \\
\text { of tool } \\
\text { electrode } \\
\text { length, } \\
\Delta l_{T E} \\
{[\mathrm{~mm}]}\end{array}$} \\
\hline & \multicolumn{2}{|c|}{ Tool diameter } & \multicolumn{2}{|c|}{ Pulse on time } & \multicolumn{2}{|c|}{ Pulse off time } & & \\
\hline & $\begin{array}{l}\text { Coded } \\
\text { value }\end{array}$ & $\begin{array}{c}d_{T E} \\
{[\mathrm{~mm}]}\end{array}$ & $\begin{array}{l}\text { Coded } \\
\text { value }\end{array}$ & $\begin{array}{l}t_{p}, \\
{[\mathrm{~s}]}\end{array}$ & $\begin{array}{l}\text { Coded } \\
\text { value }\end{array}$ & $\begin{array}{l}t b, \\
{[\mathrm{~s}]}\end{array}$ & & \\
\hline 1 & 0 & 0.6 & 0 & 0.11 & 0 & 0.03 & 0.011166 & 4.4286 \\
\hline 2 & 0 & 0.6 & 0 & 0.11 & 1 & 0.06 & 0.01279 & 5.1254 \\
\hline 3 & 0 & 0.6 & 1 & 0.22 & 0 & 0.03 & 0.013808 & 5.5242 \\
\hline 4 & 0 & 0.6 & 1 & 0.22 & 1 & 0.06 & 0.015344 & 6.0772 \\
\hline 5 & 1 & 2.6 & 0 & 0.11 & 0 & 0.03 & 0.00096 & 0.6588 \\
\hline 6 & 1 & 2.6 & 0 & 0.11 & 1 & 0.06 & 0.001134 & 0.4525 \\
\hline 7 & 1 & 2.6 & 1 & 0.22 & 0 & 0.03 & 0.000082 & 1.1619 \\
\hline 8 & 1 & 2.6 & 1 & 0.22 & 1 & 0.06 & 0.000274 & 0.7717 \\
\hline
\end{tabular}

\section{Experimental research}

The experiments were developed on a Sodick A3DL ram electrical discharge machine. As input factors, one considered the tool electrode diameter $d_{T E}$, pulse on time $t_{p}$, the pulse off time $t_{b}$. 
The test pieces were made of high speed steel (HS14-0-1-4), containing $14.31 \%$ tungsten, $4.64 \%$ cobalt, $4.09 \%$ chrome, $1.43 \%$ vanadium, $0.69 \%$ manganese.

The material of tool electrode was electrotechnical copper. Two diameters of tool electrode were taken into consideration, $d_{\text {TEmin }}=0.6 \mathrm{~mm}$ and $d_{\text {TEmax }}=2.6 \mathrm{~mm}$. As output factors, one considered the decrease of tool diameter length $\Delta l_{T E}$ and decrease of tool mass $\Delta m_{T E}$, respectively. The lengths of tool electrodes were measured just by means of the machine tool subsystem for control of distinct linear parameters, while a Partner type analytical balance was used in order to determine the tool electrode mass before and after each experiment.

The values of the input factors and of the output parameters were included in Table 1; one inscribed both the coded values and the proper values of the input factors.

The experimental results presented in Table 1 were mathematically processed by means of adequate software [5] and the following empirical mathematical relationships were determined:

- In the case of tool electrode massic wear:

$$
u_{m}=0.002358 d^{2.391} t_{p}{ }^{-1.257} t_{b}{ }^{0.582},
$$

for which the value of the Gauss's criterion is:

$$
S_{G}=4.15566 \cdot 10^{-5}
$$

- In the case of tool electrode linear wear:

$$
u_{l}=3.707 d^{-1.368} t_{p}^{0.563} t_{b}^{-0.220}
$$

for which the value of the Gauss's criterion is :

$$
S_{G}=0.547565
$$

The values of the Gauss's criterion is determined as a sum of the least squares corresponding to the differences between the measured values and the values calculated by means of the selected model, for the same experimental points [5].

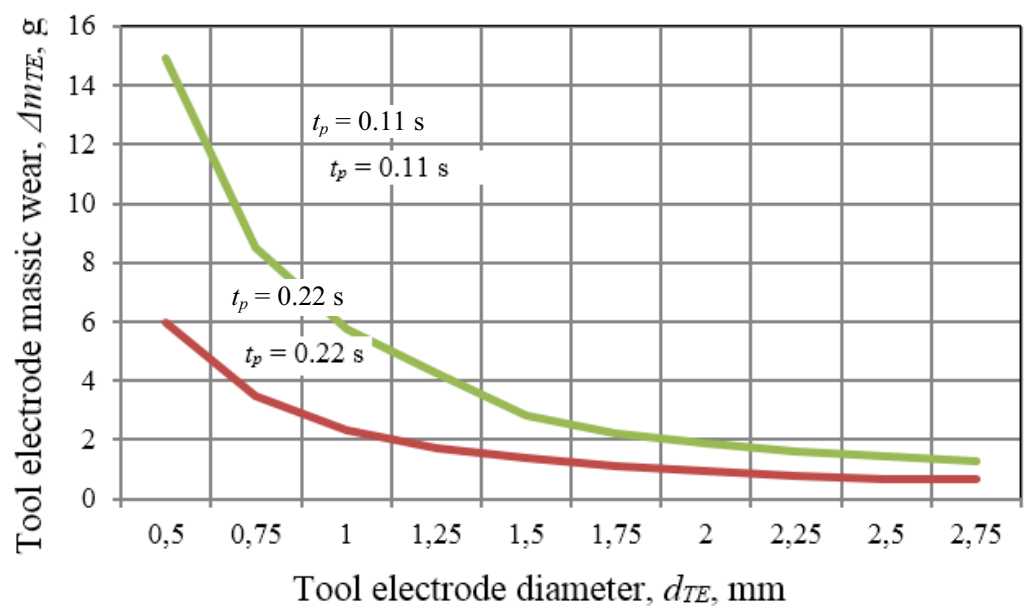

Fig. 3. Influence exerted by the tool electrode diameter on the massic tool electrode wear $\left(t_{b}=0.03 \mathrm{~s}\right.$, test piece made of high speed steel HS14-0-1-4, tool electrode material: electrotechnical copper, process duration: $40 \mathrm{~min}$ ). 
On the base of the empirical mathematical models constituted by the relationships (3) and (5), the graphical representations from Fig. 3 and Fig. 4 were elaborated, in order to highlight the intensity of the influence exerted by the values of the input factors on the values of the output parameters.

As one can see by the examination of the empirical mathematical models corresponding to the tool electrode massic and linear wear, the increase of the tool electrode diameter determines a decrease of the tool electrode wear and the fact could be explained by improving the process of heat evacuation from the tool electrode active zone when the tool electrode diameter is higher. Indeed, the higher mass of the tool electrode and the higher conductivity of the copper (compared with the electric conductivity of the dielectric liquid) ensure the conditions of faster decrease of the temperature immediately after the electrical discharge is finished and, thus, a decrease of the tool electrode wear could be identified.

If in the case of the empirical mathematical models valid for the tool electrode massic and linear wear a similar influence exerted by the tool electrode diameter could be observed, in the case of the influence of pulse on time and pulse off time there are some differences and these could be generated by the necessity to use the power type empirical functions, instead of more adequate empirical functions.

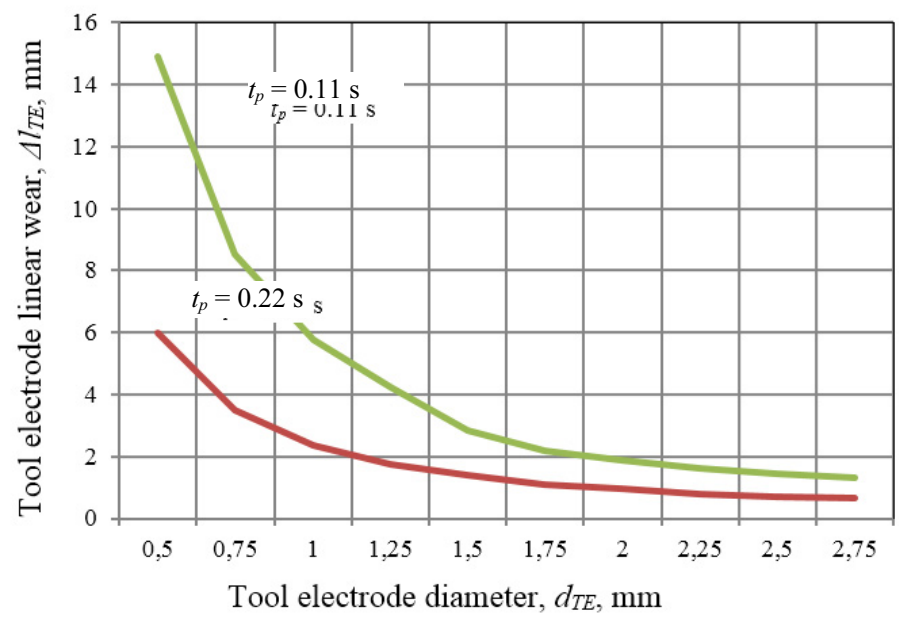

Fig. 4. Influence exerted by the tool electrode diameter $d$ on the linear tool electrode wear $\left(t_{b}=0.03 \mathrm{~s}\right.$, test piece made of high speed steel HS14-0- 1-4, tool electrode material: electrotechnical copper, process duration: $40 \mathrm{~min}$ ).

\section{Conclusions}

In the case of workpieces made of materials characterized by a low machinability by classical machining methods, the ram electrical discharge machining could constitute a solution applicable in order to obtain small diameter holes. The problem of obtaining small diameter holes in workpieces made of high speed steel was formulated. A full factorial experiment with three independent variables (tool electrode diameter, pulse on time and pulse off time) was designed in order to highlight the influence exerted by the input factors on the massic and linear tool electrode wear. By mathematical processing of the experimental results, power type empirical mathematical models were determined. These models confirmed the expected decrease of the tool electrode wear when the tool electrode diameter increases, due to the improvement of the conditions for the heat evacuation from the work zone. In the future, there is the intention to extend the experimental research 
concerning the tool electrode wear, in order to better understand the process of wear evolution in the case of electrical discharge obtaining of small diameter holes.

\section{References}

1. Y. Jiang, W. Zhao, X. Xi, L. Gu, , J. of Mechanical Science and Technology, 26, 6, $1885(2012)$

2. G. D’Urso, G. Maccarini, C. Ravasio, , Int J Adv Manuf Technol, 72, 1287 (2014)

3. B.A. Artamonov, A.L., Vishnitskiy, I.S. Volkov, A.B. Glazkov, Dimensional electrical metalworking (Vysşhaia Şkola, Moskva, 1978)

4. I. Carp, Theoretical and experimental study of processing small dimension surfaces by electrical erosion process, $\mathrm{PhD}$ Thesis (Gheorghe Asachi Technical University of Iași, 2010)

5. G. Creţu, Basics of experimental research. Laboratory guide, (Gheorghe Asachi Technical University of Iasi, 1992) 